ISSN = 1980-993X - doi:10.4136/1980-993X
www.ambi-agua.net
E-mail: ambi-agua@agro.unitau.br
Tel.: (12) 3625-4212

\title{
O estudo das unidades de paisagem do bioma Pantanal
}

(http://dx.doi.org/10.4136/ambi-agua.826)

\author{
Gabriel Pereira $^{1,3}$; Eduardo Salinas Chávez ${ }^{2}$ : Maria Elisa Siqueira Silva ${ }^{3}$ \\ ${ }^{1}$ Instituto Nacional de Pesquisas Espaciais - DSR, INPE - Brasil \\ e-mail: gabriel@dsr.inpe.br \\ ${ }^{2}$ Universidad de la Habana - Cuba. \\ e-mail: esalinas@geo.uh.cu \\ ${ }^{3}$ Universidade de São Paulo - FFLCH, USP - Brasil \\ e-mail: gabrielpereira@usp.br; elisasiq@usp.br
}

\section{RESUMO}

A observação geoecológica da paisagem permite a análise da fragmentação dos geossistemas em pequenas áreas ou mesmo um diagnóstico de um determinado ambiente ou bioma. Esta abordagem geossistêmica permite alcançar um nível superior de integração dos elementos que compõe o meio, abrangendo a análise da interação e interdependência dos elementos ambientais e sociais. O presente estudo teve como objetivo principal elaborar um mapa de unidades de paisagem e um modelo de ocupação e uso para o Bioma Pantanal, utilizando os dados provenientes do Instituto Brasileiro de Geografia e Estatística (IBGE) correspondentes às informações de unidades morfométricas de relevo, geologia, solos e potencial agrícola; o mapa de uso e cobertura da terra desenvolvido pela Empresa Brasileira de Pesquisa Agropecuária (EMBRAPA) e os mapas de áreas alagadas do bioma Pantanal e de variabilidade espacial das inundações. A partir do cruzamento entre as variáveis altimetria, declividade, mapa de variabilidade espacial e geologia, foram identificadas 16 unidades de paisagem. Ainda, a análise da vulnerabilidade ambiental das unidades de paisagem do Bioma Pantanal aos diferentes tipos de fitofisionomias, unidades morfométricas e solos mostrou que grande parte do Pantanal apresenta uma média fragilidade ambiental, localizada principalmente na região de deposição aluvial do leque do Rio Taquari e em planícies não inundáveis com altitude entre 50 e 250 metros.

Palavras-chave: Pantanal; estudo da paisagem; inundações periódicas.

\section{The study of landscape units in Pantanal biome}

\begin{abstract}
The geoecological landscape observation allows the analysis of geosystems fragmentation in small areas or a diagnosis of a particular environment or biome. This geosystemic approach permits the integration of elements that constitutes the environment, allowing the interaction and interdependence analysis of social and ecological elements. The main goal of this work was to elaborate a map of landscape units and a territorial planning for Pantanal biome, using data generated by the Brazilian Institute of Geography and Statistics (IBGE) corresponding to morphometric relief units, geology, soils and agricultural capability; the land cover and land use map developed by the Brazilian Agricultural Research Corporation (EMBRAPA) and the maps of flooded areas and spatial variability of the Pantanal biome. From the crosstab between altitude, slope, spatial variability map and geology we identified 16 landscape units.
\end{abstract}


Additionally, the analysis of Pantanal biome environmental vulnerability of the landscape units considering different types of vegetation, topography and soils units showed that Pantanal has an intermediate environmental fragility, located mainly in the alluvial deposition areas of the Taquari river and in flood plains with altitude between 50 and 250 meters.

Keywords: Pantanal; landscape; periodic flooding regime.

\section{INTRODUÇÃO}

Anualmente vastas extensões da superfície terrestre são submetidas a processos de degradação ambiental, ocasionando, desta forma, alterações significativas no uso e cobertura da terra. No Brasil, as modificações das fisionomias naturais em áreas antrópicas estão relacionadas com a constante expansão agrícola e pecuária. Consequentemente, o Pantanal, localizado em uma faixa de contato e de grande interação entre ecossistemas terrestres e aquáticos, é considerado um espaço de tensão ecológica e de grande importância socioeconômica.

O Pantanal é uma das maiores planícies sujeitas a inundações periódicas do globo. Localizado na região central da América do Sul, está localizado principalmente nas áreas dos Estados brasileiros do Mato Grosso e Mato Grosso do Sul, na Bolívia e no Paraguai. Este bioma possui fronteira com a Floresta Amazônica, ao norte, e com o platô do Brasil central, a leste, e ocupa aproximadamente $160.000 \mathrm{~km}^{2}$ do território brasileiro. As principais feições fitoecológicas presentes são compostas pela Savana Arborizada, Savana Florestada, Savana Gramíneo-lenhosa, Pastagem e Floresta Estacional Semi-decidual Aluvial (Brasil, 2010).

Localizado na bacia hidrográfica do Alto Paraguai, o bioma Pantanal é caracterizado por apresentar baixos valores hipsométricos com pequenas variações no gradiente topográfico, (Figura 1), e por uma ampla área de planícies que alagam durante a estação chuvosa, porém, sendo comum encontrar cordões arenosos que não são afetados pelas grandes inundações (Assine, 2005). Nestas planícies alagáveis, é comum a ocorrência de feições geomorfológicas de erosão e deposição que constituem a paisagem pantaneira. Entre os principais processos geomorfológicos, podem-se citar as deposições aluviais e lacustres atuais, assim como deposições aluviais antigas e paisagens formadas por processos eólicos (Assine e Soares, 2004).

O regime pluviométrico no pantanal apresenta duas estações bem definidas: uma chuvosa que ocorre entre os meses de outubro e março e outra seca, entre abril e setembro. Segundo a classificação de Köppen, o Bioma Pantanal está inserido no grupo de Clima tropical com estação seca ou clima de savana (Aw) e exibe temperaturas médias mensais superiores a $18^{\circ} \mathrm{C}$ com um dos meses com precipitação média inferior a $60 \mathrm{~mm}$. Entre os principais mecanismos de precipitação destacam-se as chuvas convectivas, ocasionadas pelo aquecimento da superfície durante o dia.

No Pantanal Brasileiro, o ciclo de alagamento anual abrange, segundo Cardozo et al. (2010), $26 \pm 7 \%$ da área total do bioma $\left(42.700 \pm 11.719 \mathrm{~km}^{2}\right)$. O efeito da mudança de cobertura atua significativamente nessa dinâmica alterando o balanço de energia, a temperatura da superfície e do ar e, consequentemente, o ciclo hidrológico regional (Pereira et al., 2010b). Tradicionalmente, os recursos naturais (bióticos e abióticos) podem ser classificados em renováveis e não renováveis, dependendo de sua taxa de regeneração no tempo e de sua utilização. Desta forma, a exploração destes recursos devem ser embasados em inventários ambientais e em zoneamentos econômico-ecológicos, onde o principal objetivo é permitir um melhor aproveitamento e gerenciamento do meio ambiente. Para atingir tal objetivo, a cartografia digital e o sensoriamento remoto apresentam-se como uma alternativa eficaz, pois essas técnicas permitem detectar, localizar e representar de maneira eficiente os recursos naturais existentes em determinada região e promover a organização do espaço (Priego et al., 2008). 
A visão geoecológica da paisagem permite estudar desde a fragmentação dos objetos em pequenas áreas até a análise sistêmica de um dado ambiente ou bioma. Esta abordagem permite alcançar um nível superior de integração dos elementos que compõe o meio-ambiente, incluindo a análise da interação e interdependência dos elementos sociais e ambientais. O estudo da paisagem ainda pode originar ordenamentos territoriais para determinadas regiões ou áreas com base nos seus atributos físicos e sociais.

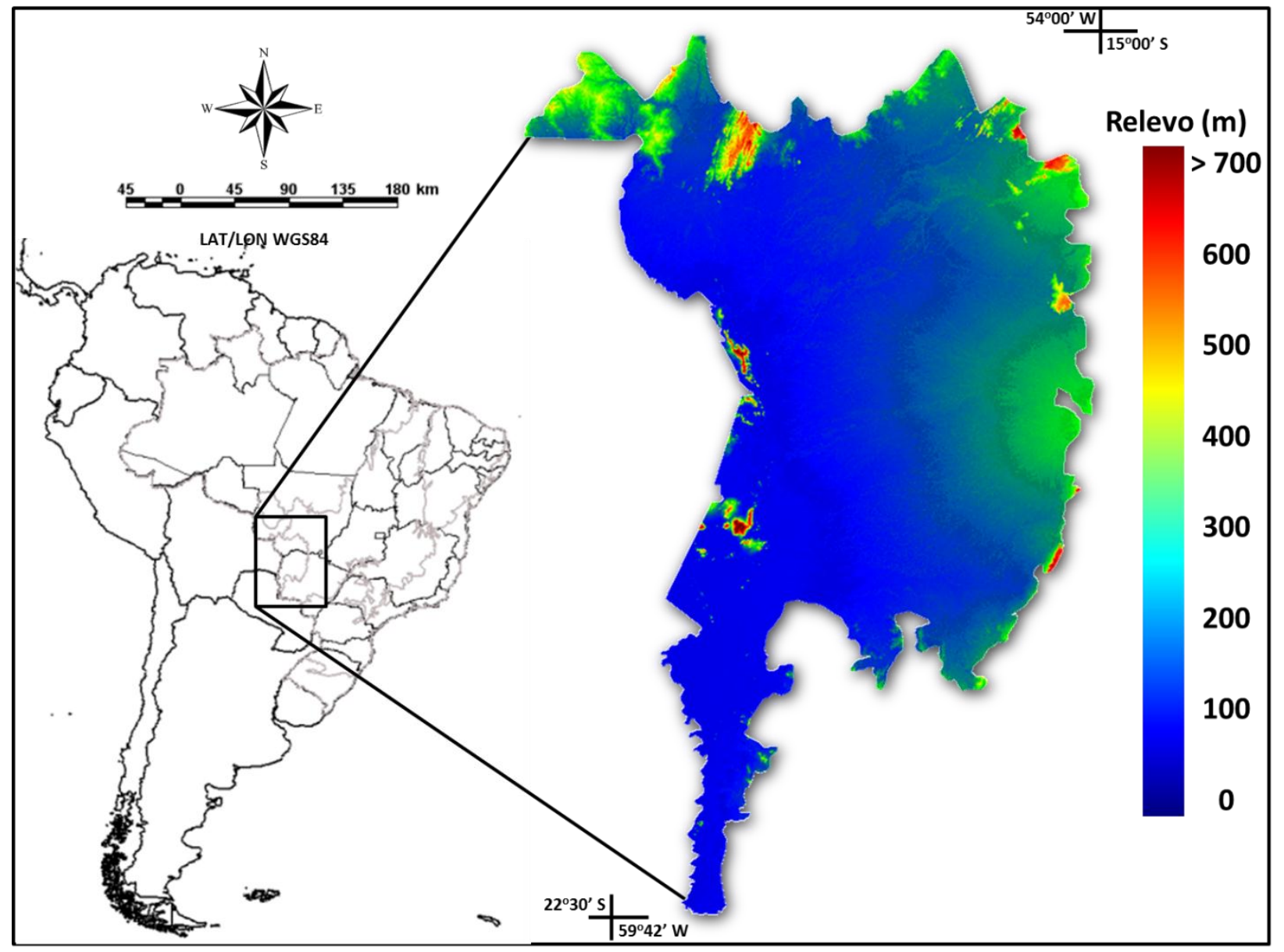

Figura 1. Localização da área de estudo.

Todavia, segundo Salinas e Middleton (1998), para propor um ordenamento territorial e analisar a sustentabilidade de diferentes regiões, torna-se necessário o conhecimento prévio dos diferentes elementos que formam a paisagem como, por exemplo, as condições climáticas, as características do relevo, as potencialidades dos solos para os diferentes usos, os distintos processos geomorfológicos que atuaram na superfície terrestre e determinaram as relações ecogeográficas, além das estruturas fitoecológicas presentes na área de estudo. Portanto, o auxílio da ecologia da paisagem, que possui um caráter holístico, apresenta-se como uma ferramenta poderosa para integrar os elementos físicos, bióticos e antrópicos que atuam no meioambiente de maneira integrada (Salinas e Quintela, 2000).

Neste contexto, o presente trabalho tem como objetivo principal analisar os principais elementos que formam a paisagem do Bioma Pantanal. Desta forma, devem-se analisar as diferentes componentes que atuam na área de estudo, integrando mapas de hipsometria, declividade, geologia, aptidão ao uso agrícola, unidades morfométricas e informações de uso e cobertura da terra para obter o mapa de Paisagem e propor um uso sustentável para a área em questão. 


\section{MATERIAIS E MÉTODO}

\subsection{Valores altimétricos e declividade}

Para a obtenção dos valores altimétricos da área de estudo utilizou-se o modelo digital de terreno (MDT) derivado de imagens interferométricas do Shuttle Radar Topography Mission (SRTM). Este dado possui como características principais a resolução espacial de 90 metros e cobertura global. Ressalta-se que os valores altimétricos foram adquiridos durante a campanha de 11 dias do ano de 2000 a partir de um sistema-radar de abertura sintética que operava nas bandas $\mathrm{C}$ e $\mathrm{X}$ na região do espectro eletromagnético referente às micro-ondas. Os dados globais de MDT derivados pelo SRTM possuem a acurácia de aproximadamente 16 metros, porém, podem-se obter erros de aproximadamente 6 metros para escalas locais, que variam de 50 a 100 km (Rabus et al., 2003).

A partir dos dados de MDT, estimou-se a declividade de cada ponto de grade do modelo. Esta etapa foi realizada no SPRING, um programa de gerenciamento e processamento de dados geográficos, desenvolvido pelo Instituto Nacional de Pesquisas Espaciais (INPE). A declividade pode ser definida como a medida de inclinação de determinado ponto do MDT em relação ao plano horizontal. De uma maneira geral, a declividade pode ser estimada a partir da equação (SPRING, 2005):

$$
\text { Declividade }=\arctan \sqrt{\frac{\partial z^{2}}{\partial x^{2}}+\frac{\partial z^{2}}{\partial y^{2}}}
$$

em que: $\mathrm{z}$ representa o valor altimétricos, $\mathrm{x}$ e y as coordenadas do ponto.

\subsection{Informações Ambientais}

Para delimitar as unidades morfológicas do Pantanal, utilizaram-se dados vetoriais provenientes do Instituto Brasileiro de Geografia e Estatística - IBGE (2011) correspondentes às informações de: a) unidades morfométricas de relevo, que apresenta as características geomorfológicas e sua relação com o domínio morfoestrutural do bioma Pantanal; b) geologia; c) solos; e d) potencial agrícola, que relaciona as componentes físicas como características morfológicas, topografia e fertilidade.

O mapa de uso e cobertura da terra utilizado neste trabalho foi originado pela EMBRAPA (2004). Este mapa foi confeccionado a partir da aplicação de segmentação (critério de crescimento de região) em imagens do sensor Thematic Mapper (TM) do satélite Landsat 5 e interpretação visual dos segmentos gerados pelo processamento da imagem. Embora o mapa tenha sido confeccionado em diversas classes de fisionomias vegetais e usos, optou-se por agrupá-lo nas classes Ecótono, Formações Pioneiras, Formações Florestais, Áreas Urbanas, Hidrografia, Agricultura/Pecuária e Savana. Ressalta-se que o mapa das áreas alagadas do bioma Pantanal, para os anos de 2000 a junho de 2010, foram extraídos de Cardozo et al. (2010), e o mapa da variabilidade espacial das inundações, obtidos a partir da realização por componentes principais, foi extraído de Pereira et al. (2010a).

\subsection{Metodologia}

Os dados vetoriais e matriciais dos produtos acima mencionados foram inseridos no SPRING. Desta forma, alguns procedimentos (transformação e compatibilização de diferentes dados, extração de atributos, entre outros) foram realizados na Linguagem Espacial para Geoprocessamento Algébrico (LEGAL). A Figura 2 mostra o fluxograma da metodologia adotada para se obter o mapa de Paisagem do Bioma Pantanal, assim como, o modelo de ocupação e uso para o Bioma Pantanal estimado a partir das unidades morfométricas, geologia, uso e cobertura da terra, potencial agrícola e solos. 
A primeira etapa da metodologia consistiu em agrupar todos os dados necessários para o estudo (I) e posterior extração de atributos e conversões para o formato matricial (II) e (III). A quarta etapa (IV) consistiu no cruzamento de diversos planos de informação para originar os mapas de unidades morfométricas e, decorrente deste, o mapa de unidades de paisagem. Esta etapa consistiu no cruzamento de diversas informações, como, por exemplo, os dados de variabilidade espacial das áreas alagadas, altimetria, declividade, unidades de relevo, geologia, solos e uso/cobertura vegetal (Ramon et al., 2009).

A Etapa V constitui na atribuição do grau de fragilidade para cada componente do Bioma Pantanal, relacionados com o tipo de vegetação, relevo, declividade e solo predominantes em cada unidade de paisagem. Desta forma, o mapa final originou-se da ponderação das fragilidades de cada componente (Muito Alta, Alta, Média, Baixa e Muito Baixa). A última etapa (VI) referese ao cruzamento de todos os elementos que constituem o Bioma Pantanal. Nesta etapa, os mapas de unidades morfométricas, unidades de paisagem, fragilidade, uso e cobertura do solo e potencial agrícola foram ponderados de acordo com a aptidão para a conservação, urbanização, agricultura/pecuária, indicando ao final o potencial primário e secundário, originando o modelo de ocupação e uso (Salinas, 2008).

(I)

(II)

(III)

(IV)

(V)

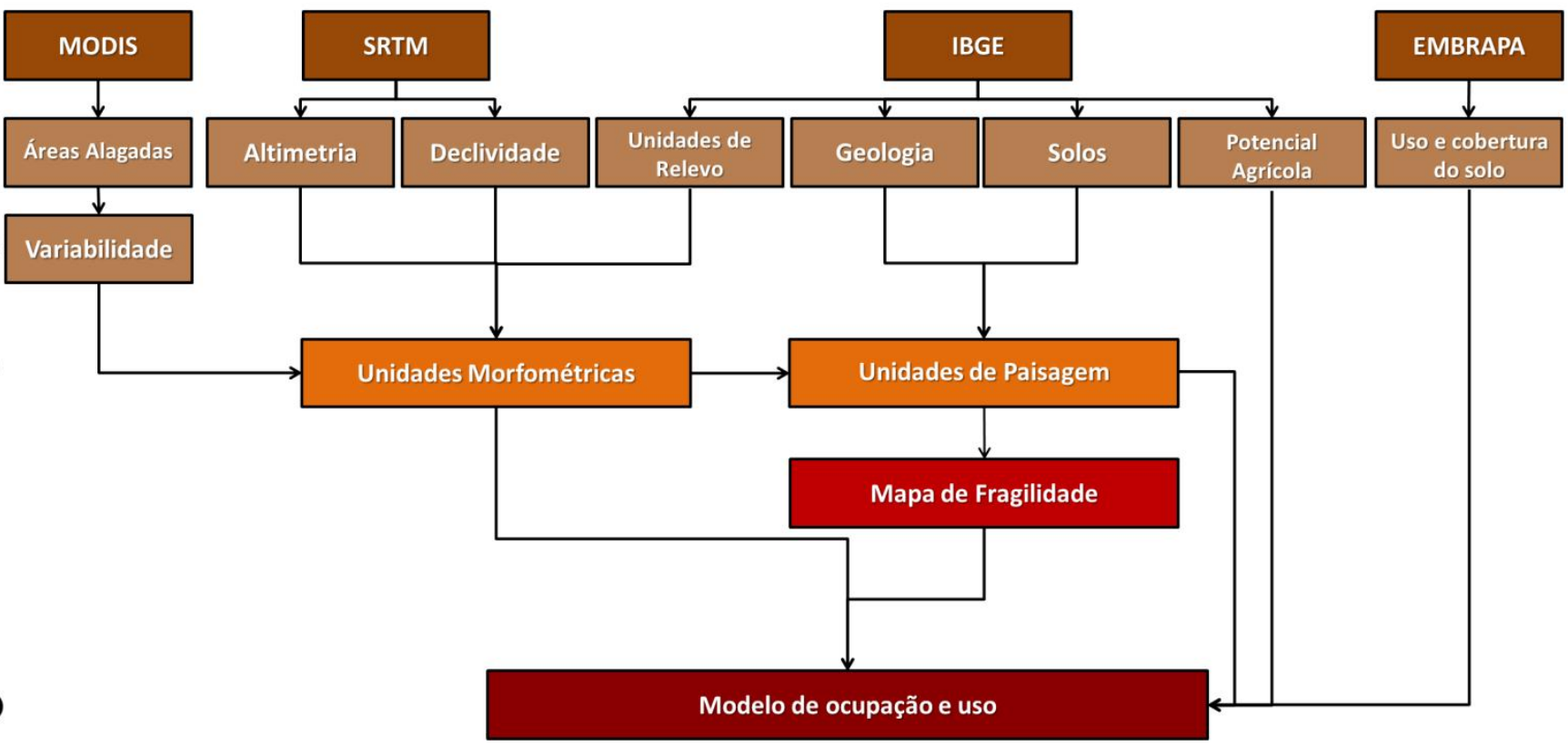

Figura 2. Fluxograma da metodologia.

\section{RESULTADOS E DISCUSSÃO}

De acordo com Cardozo et al. (2010), o ciclo de alagamento anual no Bioma Pantanal abrange $42.700 \pm 11.719 \mathrm{~km}^{2}$. Segundo estes autores, as maiores áreas alagadas ocorreram no ano de 2000, seguidas do ano de 2007, 2006 e 2008, possuindo $58.490 \mathrm{~km}^{2}, 55.250 \mathrm{~km}^{2}, 54.490$ $\mathrm{km}^{2}$ e $54.320 \mathrm{~km}^{2}$, correspondendo a 36,55\%, 34,53\%, 34,05\% e 33,95\% da área total, respectivamente. Pode-se dizer que o Bioma Pantanal apresenta grande dinâmica intra e interanual, fato observado pela variação das inundações que ocorreram por todo o bioma entre os anos de menor e maior alagamento, com diferenças superiores a 57\%. 
No Pantanal, o regime das inundações determina os principais processos bióticos e abióticos, bem como as composições específicas das unidades da paisagem (Adamoli, 1995). Todo o bioma é influenciado pelas alterações no regime de inundações, causando mudanças na cobertura vegetal.

A Figura 3 mostra as segundas componentes principais (PC2) geradas a partir dos dados de NDVI (índice de vegetação por diferença normalizada) e reflectância NIR/SWIR, respectivamente, provenientes da série temporal disponibilizada pelos dados do sensor MODIS (Justice et al., 2002) a bordo do satélite Terra. Nestas componentes podemos visualizar a dinâmica interanual da vegetação (Figura 3a) e a variação das áreas alagadas no decorrer dos anos (Figura 3b). Percebe-se uma diversificada dinâmica ocasionada pela época chuvosa e pela resposta da vegetação ao stress hídrico que ocorre na vegetação do pantanal. Na Figura 3b as regiões com tons de vermelho são cobertas por lâminas d'água na estação chuvosa, resultando em lagos temporários extensos, que inundam a vegetação existente. Após a inundação a vegetação volta a ficar exposta, ocupando a área.
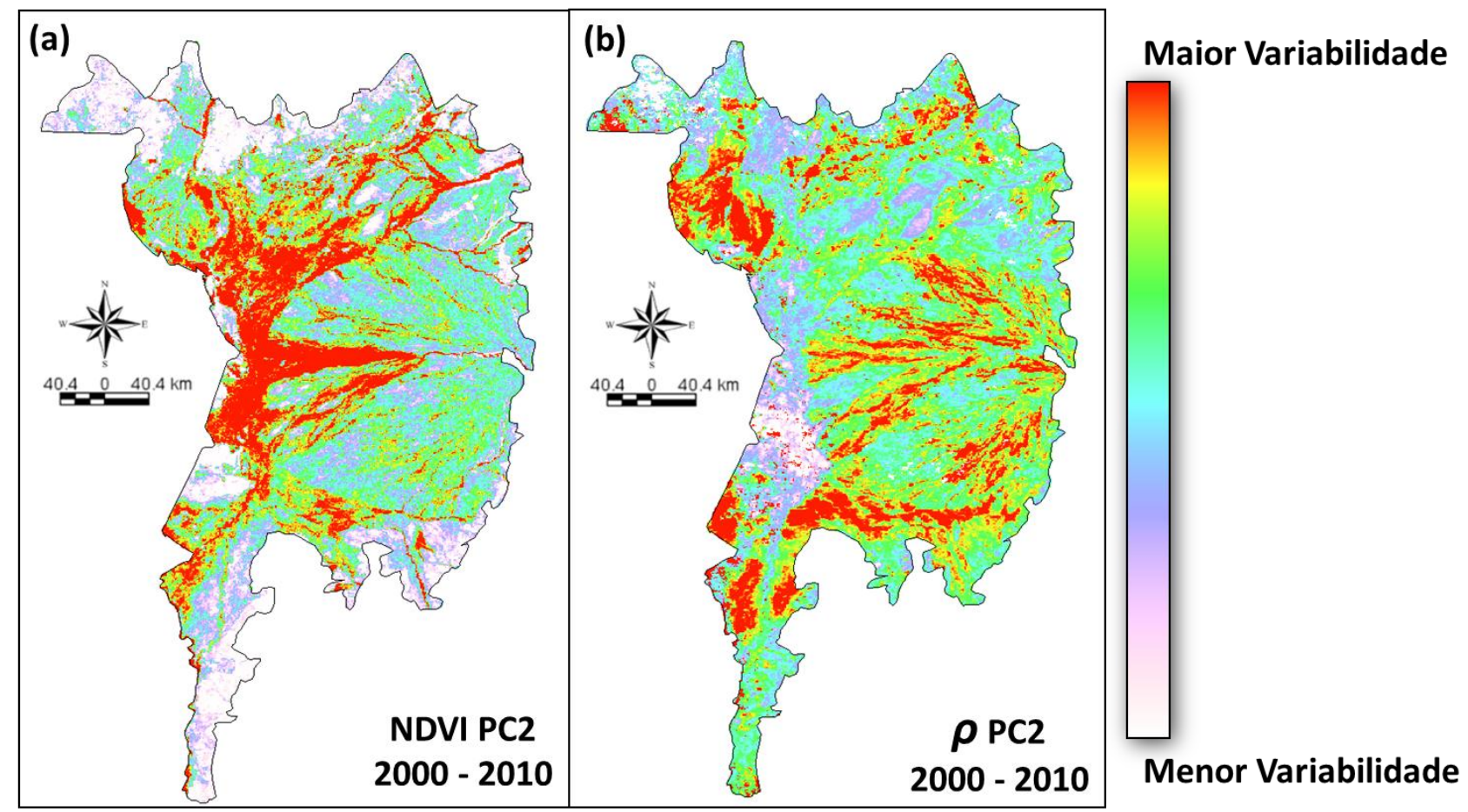

Figura 3. Mapa da variabilidade obtida a partir da componente principal CP2 das imagens NDVI (à esquerda) e de reflectância ( $\rho)$ NIR/SWIR (à direita).

Fonte. Adaptado de Pereira et al. (2010a).

A Figura 4 mostra o mapa hipsométrico, o mapa de declividade e as unidades morfométricas de relevo para a área de estudo. Para o Bioma Pantanal, aproximadamente $83 \%$ da área possui plana a baixa declividade (0-2.5\%) e altitude entre 50-150 metros. Além disto, $14 \%$ da área de estudo apresentam baixa a média declividade (2.5-12\%) e altitude predominante entre 50-150 metros, sendo que apenas $3 \%$ da área apresentam um relevo com média a alta declividade (12$50 \%$ ) ou declividade muito alta $(>50 \%)$. Desta forma, optou-se por separar as unidades morfométricas em quatro grandes regiões, adotando-se a nomenclatura oficial do Instituto Brasileiro de Geografia e Estatística (IBGE). A Figura 4c mostra a distribuição destas unidades: em (1) a classe correspondente à Depressão dos Altos Rios Paraguai/Guaporé; em (2) os Pantanais Mato-grossenses, referentes à planície de inundação; em (3) o Planalto dos Guimarães, 
com topos suaves e moderados; e (4) referentes aos Planaltos e Serras dos Altos Rios Paraguai/Guaporé.
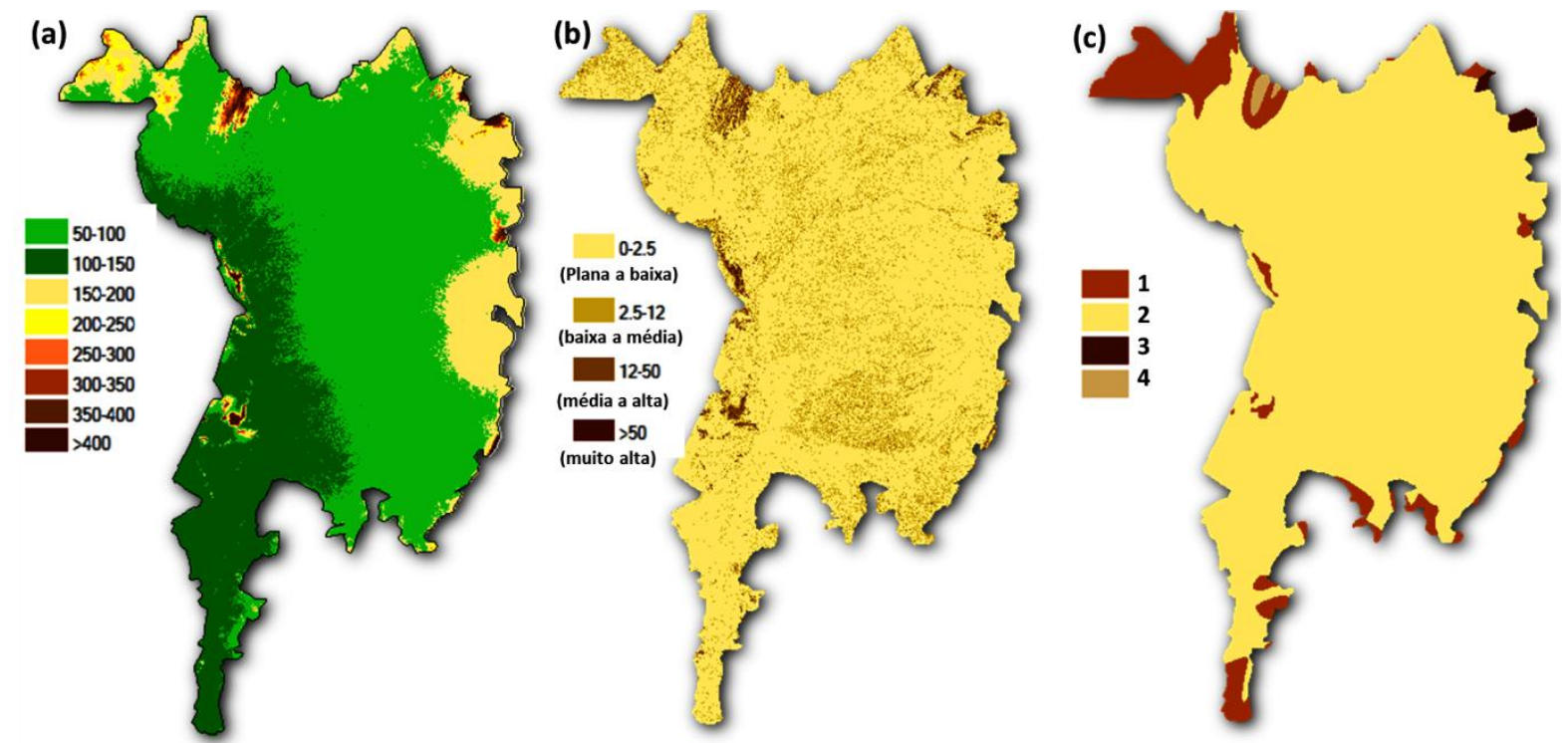

Figura 4. (a) Mapa hipsométrico extraído do SRTM; (b) Mapa da declividade; e (c) Mapa de unidades morfométricas provenientes do IBGE (2011).

A Figura 5a mostra o mapa das unidades morfométricas, com o acréscimo das áreas de alta variabilidade para o Bioma Pantanal, obtido a partir da análise por componentes principais da região do espectro eletromagnético referente ao NIR/SWIR (como visualizado na Figura 3b). Desta forma, as cinco classes referentes às unidades morfométricas representam: (1) Planícies aluviais não inundáveis (50-100 m) de plana a média declividade (0-12\%); (2) Planícies Aluviais inundáveis $(50-100 \mathrm{~m})$ de plana a baixa declividade (0-2,5\%); (3) Depressão dos Altos Rios Paraguai/Guaporé $(150-250 \mathrm{~m})$ com baixa a média declividade (2,5-12\%); (4) Planalto dos Guimarães (250-600 m) com declividade muito alta (>50\%); e (5) Planaltos e Serras dos Altos Rios Paraguai/Guaporé $(>400 \mathrm{~m})$ com declividade muito alta $(>50 \%)$. A Tabela 1 mostra as unidades geológicas para da área de estudo.

(a)

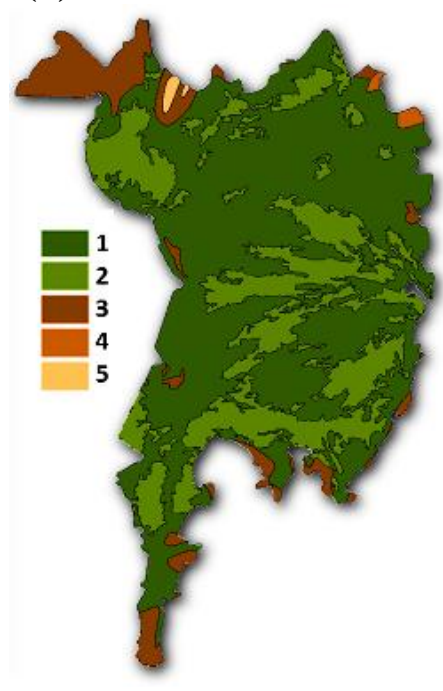

(b)

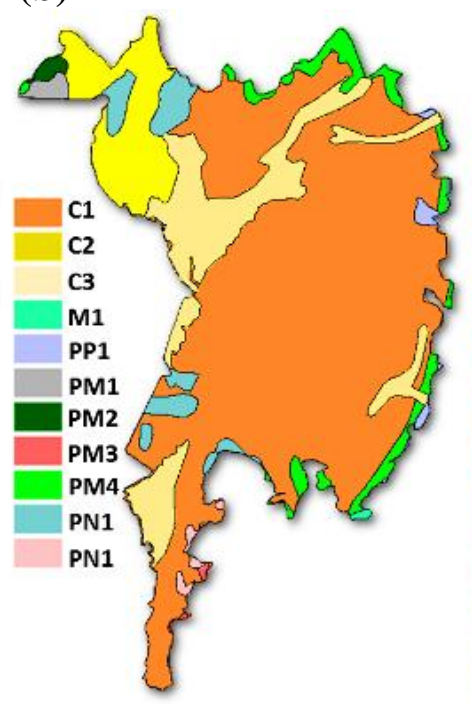

(c)

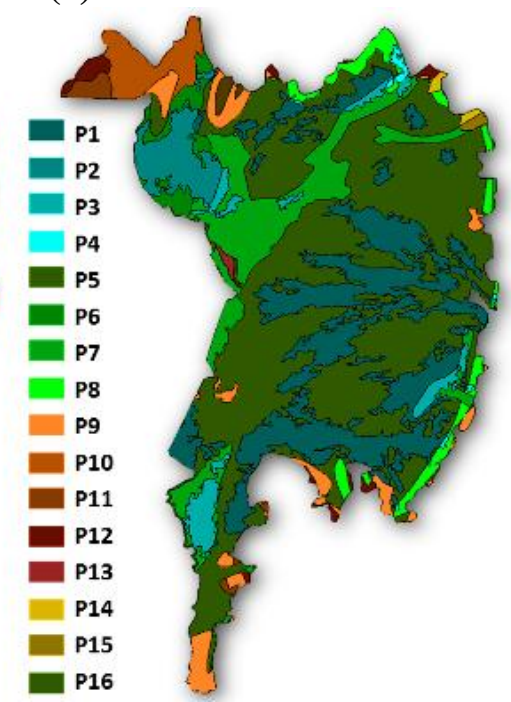

Figura 5. (a) Mapa de unidades morfométricas com a área de alta variabilidade; (b) Mapa da geologia para o Bioma Pantanal extraído de IBGE (2011); e (c) Mapa das unidades de Paisagem para o Bioma Pantanal. 
A partir do mapa de unidades morfométricas com áreas de alta variabilidade e o mapa de geologia obtido a partir do IGBE, originou-se o mapa de unidades de Paisagem. A Figura 5b representa as classes geológicas para a área de estudo, em que cada código na legenda representa:

Tabela 1. Unidades geológicas para a área de estudo.

\begin{tabular}{|c|c|}
\hline $\mathrm{C} 1$ & $\begin{array}{l}\text { Sedimentos arenosos e argilosos, podendo incluir níveis carbonosos do } \\
\text { Terciário. }\end{array}$ \\
\hline $\mathrm{C} 2$ & Sedimento arenoso do Pleistoceno. \\
\hline $\mathrm{C} 3$ & Sedimentos relativos à aluviões atuais e terraços mais antigos do Holoceno. \\
\hline PN1 & Sedimentos arenosos e argilo-carbonáticos de grau metamórfico fraco a médio. \\
\hline PM1 & $\begin{array}{l}\text { Rochas gnáissicas de origem magmática e/ou sedimentar de médio grau } \\
\text { metamórfico. }\end{array}$ \\
\hline PM2 & $\begin{array}{l}\text { Sequências sedimentares e vulcanossedimentares de grau metamórfico baixo a } \\
\text { médio. }\end{array}$ \\
\hline PM3 & $\begin{array}{l}\text { Associações de rochas de origem vulcânica e plutônica e composição félsica até } \\
\text { máfica. }\end{array}$ \\
\hline PM4 & $\begin{array}{l}\text { Sequências sedimentares, principalmente psamíticas, podendo incluir } \\
\text { piroclásticas. }\end{array}$ \\
\hline M1 & Sedimentos argilosos, arenosos e cascalhos. \\
\hline PP1 & $\begin{array}{l}\text { Rochas gnáissicas de origem magmática e/ou sedimentar de médio grau } \\
\text { metamórfico e rochas graníticas desenvolvidas durante o tectonismo. }\end{array}$ \\
\hline
\end{tabular}

A Figura 5c mostra o mapa das unidades de Paisagem obtidas a partir do cruzamento entre as variáveis altimetria, declividade, mapa de variabilidade espacial e geologia. Para a área de estudo, foram identificadas 16 unidades de paisagem (Tabela 2). 
PEREIRA, G.; CHÁVEZ, E. S.; SILVA, M. E. S. O estudo das unidades de paisagem do bioma Pantanal. AmbiAgua, Taubaté, v. 7, n. 1, p. 89-103, 2012. (http://dx.doi.org/10.4136/ambi-agua.826)

Tabela 2. Unidades de Paisagem para o Bioma Pantanal.

\begin{tabular}{|c|c|}
\hline P1 & $\begin{array}{l}\text { Planície aluvial sujeita a inundações periódicas }(50-150 \mathrm{~m}) \text { com predominância de declividade plana a } \\
\text { baixa }(0-2,5 \%) \text { com sedimentos arenosos e argilosos, podendo incluir sedimentos argilo-carbonáticos e } \\
\text { cascalhos, com solo predominantemente do tipo Espodossolo Ferrocárbico, com Savana/Pastagem. }\end{array}$ \\
\hline P2 & $\begin{array}{l}\text { Planície aluvial sujeita a inundações periódicas }(50-150 \mathrm{~m}) \text { com predominância de declividade plana a } \\
\text { baixa }(0-2,5 \%) \text { com sedimentos arenosos do Pleistoceno, com solo predominantemente do tipo } \\
\text { Plintossolo Háplico, com Savana/Savana Lenhosa. }\end{array}$ \\
\hline P3 & $\begin{array}{l}\text { Planície aluvial sujeita a inundações periódicas }(50-150 \mathrm{~m}) \text { com predominância de declividade plana a } \\
\text { baixa }(0-2.5 \%) \text { com sedimentos relativo à aluviões atuais e terraços mais antigos do Holoceno, com } \\
\text { solo predominantemente do tipo Planossolo Hidromórfico, com Savana/Savana Lenhosa. }\end{array}$ \\
\hline P4 & $\begin{array}{l}\text { Planície aluvial sujeita a inundações periódicas }(50-150 \mathrm{~m}) \text { com predominância de baixa a média } \\
\text { declividade }(2,5-12 \%) \text { com sequências sedimentares, principalmente psamíticas, podendo incluir } \\
\text { piroclásticas, com solo predominantemente do tipo Plintossolo Háplico, com Savana/ Floresta } \\
\text { Estacional. }\end{array}$ \\
\hline P5 & $\begin{array}{l}\text { Planície aluvial não inundável }(50-150 \mathrm{~m}) \text { com predominância de declividade plana a baixa }(0-2,5 \%) \\
\text { com sedimentos arenosos e argilosos, podendo incluir sedimentos argilo-carbonáticos e cascalhos, com } \\
\text { solo predominantemente do tipo Espodossolo Ferrocárbico, com Savana/Floresta Estacional. }\end{array}$ \\
\hline P6 & $\begin{array}{l}\text { Planície aluvial não inundável }(50-150 \mathrm{~m}) \text { com predominância de declividade plana a baixa }(0-2,5 \%) \\
\text { com sedimentos arenosos do Pleistoceno, com solo predominantemente do tipo Plintossolo Háplico, } \\
\text { com Savana/ Floresta Estacional. }\end{array}$ \\
\hline P7 & $\begin{array}{l}\text { Planície aluvial não inundável }(50-150 \mathrm{~m}) \text { com predominância de declividade plana a baixa }(0-2,5 \%) \\
\text { com sedimentos relativo à aluviões atuais e terraços mais antigos do Holoceno, podendo incluir } \\
\text { sequências sedimentares e vulcanossedimentares de grau metamórfico baixo a médio, com solo } \\
\text { predominantemente do tipo Gleissolo Háplico, com Floresta Estacional /Savana Lenhosa. }\end{array}$ \\
\hline P8 & $\begin{array}{l}\text { Planície aluvial não inundável }(50-150 \mathrm{~m}) \text { com predominância de baixa a média declividade }(2,5-12 \%) \\
\text { com sequências sedimentares, principalmente psamíticas, podendo incluir piroclásticas, com solo } \\
\text { predominantemente do tipo Argissolo Vermelho-Amarelo, com Savana/Savana Lenhosa. }\end{array}$ \\
\hline P9 & $\begin{array}{l}\text { Depressão dos Altos Rios Paraguai/Guaporé }(150-250 \mathrm{~m}) \text { com predominância de baixa a média } \\
\text { declividade }(2,5-12 \%) \text { com sedimentos arenosos e argilosos, podendo incluir sedimentos argilo- } \\
\text { carbonáticos e cascalhos, com solo predominantemente do tipo Argissolo Vermelho-Amarelo, com } \\
\text { Savana/Savana Lenhosa. }\end{array}$ \\
\hline P10 & $\begin{array}{l}\text { Depressão dos Altos Rios Paraguai/Guaporé }(150-250 \mathrm{~m}) \text { com predominância de baixa a média } \\
\text { declividade }(2,5-12 \%) \text { com sedimentos arenosos do Pleistoceno, com solo predominantemente do tipo } \\
\text { Argissolo Vermelho-Amarelo, com Savana/Agricultura e Pecuária. }\end{array}$ \\
\hline P11 & $\begin{array}{l}\text { Depressão dos Altos Rios Paraguai/Guaporé }(150-250 \mathrm{~m}) \text { com predominância de baixa a média } \\
\text { declividade }(2,5-12 \%) \text { com rochas gnáissicas de origem magmática e/ou sedimentar de médio grau } \\
\text { metamórfico e rochas graníticas desenvolvidas durante o tectonismo, com solo predominantemente do } \\
\text { tipo Planossolo Háplico, com Savana/Savana Lenhosa. }\end{array}$ \\
\hline P12 & $\begin{array}{l}\text { Depressão dos Altos Rios Paraguai/Guaporé }(150-250 \mathrm{~m}) \text { com predominância de baixa a média } \\
\text { declividade }(2,5-12 \%) \text { com sequências sedimentares/vulcanossedimentares e associações de rochas de } \\
\text { origem vulcânica e plutônica, com solo predominantemente do tipo Argissolo Vermelho-Amarelo, } \\
\text { com Savana/Savana Lenhosa. }\end{array}$ \\
\hline P13 & $\begin{array}{l}\text { Depressão dos Altos Rios Paraguai/Guaporé }(150-250 \mathrm{~m}) \text { com predominância de baixa a média } \\
\text { declividade }(2,5-12 \%) \text { com sedimentos relativos à aluviões atuais e terraços mais antigos do Holoceno, } \\
\text { com solo predominantemente do tipo Argissolo Vermelho-Amarelo, com Savana Lenhosa/Pastagem. }\end{array}$ \\
\hline P14 & $\begin{array}{l}\text { Planalto dos Guimarães }(250-600 \mathrm{~m}) \text { com predominância de muito alta declividade }(>50 \%) \text { com } \\
\text { sedimentos relativos à aluviões atuais e terraços mais antigos do Holoceno, com solo } \\
\text { predominantemente do tipo Argissolo Vermelho-Amarelo, com Savana/Agricultura e Pecuária. }\end{array}$ \\
\hline P15 & $\begin{array}{l}\text { Planalto dos Guimarães }(250-600 \mathrm{~m}) \text { com predominância de muito alta declividade }(>50 \%) \text { com } \\
\text { sequências sedimentares, podendo incluir sedimentos arenosos e argilosos, com solo } \\
\text { predominantemente do tipo Argissolo Vermelho-Amarelo, com Savana Lenhosa/Savana. }\end{array}$ \\
\hline P16 & $\begin{array}{l}\text { Planaltos e Serras dos Altos Rios Paraguai/Guaporé }(>400 \mathrm{~m}) \text { com muito alta declividade (>50\%) com } \\
\text { sedimentos arenosos e argilo-carbonáticos de grau metamórfico fraco a médio, com solo } \\
\text { predominantemente do tipo Argissolo Vermelho-Amarelo, com Savana/Savana Lenhosa. }\end{array}$ \\
\hline
\end{tabular}


A Figura 6a mostra o mapa de fragilidade ambiental para o Bioma Pantanal. Este mapa representa a vulnerabilidade ambiental das unidades de paisagem do Bioma Pantanal aos diferentes tipos de fitofisionomias, unidades morfométricas e solos. Percebe-se que grande parte do Pantanal apresenta uma média fragilidade ambiental, localizada principalmente na região de deposição aluvial do leque do Rio Taquari e em planícies não inundáveis com altitude entre 50 e 250 metros. As áreas de baixa fragilidade ambiental estão localizadas em planícies de deposição aluvial com predominância de plana a baixa declividade (0-2,5\%) com sedimentos relativos a aluviões atuais e terraços mais antigos do Holoceno, com predomínio de Savana/Savana Lenhosa. Além disto, áreas de alta e muito alta fragilidade são compostas por regiões de planícies aluviais e regiões montanhosas com média e alta declividade, compostas principalmente por solos do tipo Planossolo Háplico, Gleissolo Háplico e Argissolo VermelhoAmarelo. A Tabela 3 mostra os valores adotados para estimativa do mapa de fragilidade para o Pantanal.

Tabela 3. Valores adotados para estimativa do mapa de fragilidade para o Pantanal.

\begin{tabular}{|c|c|c|c|c|c|}
\hline & Muito Alta & Alta & Média & Baixa & $\begin{array}{l}\text { Muito } \\
\text { Baixa }\end{array}$ \\
\hline Vegetação & $\begin{array}{l}\text { Floresta } \\
\text { Estacional }\end{array}$ & $\begin{array}{l}\text { Savana Lenhosa } \\
\text { Savana } \\
\text { Arborizada }\end{array}$ & Savana & Gramíneas & $\begin{array}{l}\text { Agricultura } \\
\text { Pecuária }\end{array}$ \\
\hline Relevo & $>400 \mathrm{~m}$ & $350-400 \mathrm{~m}$ & $250-350 \mathrm{~m}$ & $150-250 \mathrm{~m}$ & $50-150 \mathrm{~m}$ \\
\hline Declividade & $>50 \%$ & $12-50 \%$ & $6-12 \%$ & $2,5-6 \%$ & $0-2,5 \%$ \\
\hline Solos & $\begin{array}{l}\text { Planossolo } \\
\text { Háplico e } \\
\text { Planossolo } \\
\text { Hidromórfico }\end{array}$ & $\begin{array}{l}\text { Argissolo } \\
\text { Vermelho- } \\
\text { Amarelo, } \\
\text { Gleissolo Háplico } \\
\text { e Plintossolo } \\
\text { Háplico }\end{array}$ & $\begin{array}{l}\text { Espodossolo } \\
\text { Férrico }\end{array}$ & ----------- & \\
\hline
\end{tabular}

A Figura 6 b mostra o mapa do potencial agrícola estimado pelo IBGE. Este mapa caracteriza o Bioma Pantanal de acordo com as potencialidades para o uso agrícola, utilizando fatores ambientais como fertilidade, topografia, principais limitações e características físicas e morfológicas de cada região. Em geral, o Bioma Pantanal apresenta uma aptidão agrícola desfavorável com aproximadamente $76 \%$ da área total $\left(121.170 \mathrm{~km}^{2}\right)$. Entre as principais limitações ao uso agrícola podem-se citar a alta salinidade, a reduzida profundidade do horizonte A e B, presença de pedregosidade ou rochosidade e a textura arenosa. Estes solos ocorrem basicamente nas planícies e regiões sujeitas a inundações periódicas.

No Pantanal, aproximadamente $12 \%$ da área apresenta um potencial agrícola caracterizado como Restrito a Desfavorável devido principalmente ao excesso de sódio e corresponderem a áreas de inundações periódicas e com restrição de drenagem. 


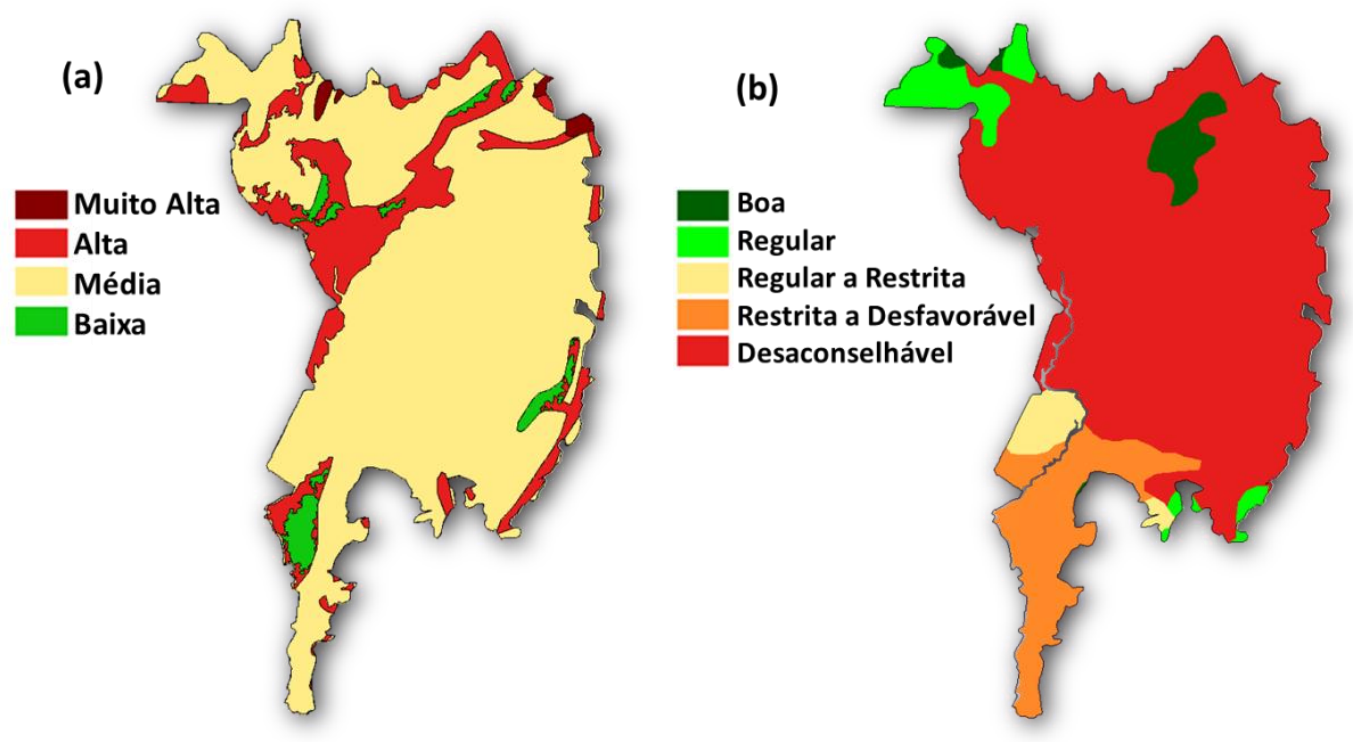

Figura 6.(a) Mapa de fragilidade para o Bioma Pantanal; (b) Mapa de potencial agrícola estimado pelo IBGE (2011).

Ainda, aproximadamente $8 \%$ apresentam uma caracterização considerada Regular a Restrita, estas regiões são caracterizadas por apresentar declives acentuados, pouca profundidade dos horizontes A e B, textura grosseira, baixa disponibilidade de nutrientes e excesso de alumínio. Apenas $4 \%$ de todo o bioma pantaneiro apresenta condições favoráveis para a agricultura com alta fertilidade, características físicas e morfológicas boas e praticamente sem limitações.

A Tabela 4 mostra os cruzamentos entre a altimetria, declividade, solos, vegetação e seus respectivos valores de suscetibilidade adotados para originar o mapa de fragilidade ambiental (Figura 6a). Ainda, pode-se observar a aptidão à conservação ambiental, urbanização e agricultura/pecuária. Estes valores foram adotados para originar a tabela de aptidão primária e secundária, determinando, desta forma, o modelo de ocupação e uso (Figura 7b).

Tabela 4. Valores de suscetibilidade adotados para o mapa de fragilidade, aptidão à conservação, urbanização e agricultura/pecuária e proposta de uso.

\begin{tabular}{|c|c|c|c|c|c|c|c|c|c|c|c|}
\hline \multirow[b]{2}{*}{ Unidade de Paisagem } & \multirow[b]{2}{*}{ Altimetria } & \multirow[b]{2}{*}{ Declividade } & \multirow[b]{2}{*}{ Solo } & \multirow[b]{2}{*}{ Vegetação } & \multirow[b]{2}{*}{ Fragilidade } & \multicolumn{3}{|c|}{ Aptidão } & \multirow[b]{2}{*}{ Aptidão Primária } & \multirow[b]{2}{*}{ Aptidão Secundária } & \multirow[b]{2}{*}{ Proposta de uso } \\
\hline & & & & & & Agric. e Pecuária & Assentamentos & Conservação & & & \\
\hline 1 & Muito Baixa & Baixa & Média & Média & Média & Não-Apto & Não-Apto & Apto & Conservação & $x$ & Conservação \\
\hline 2 & Muito Baixa & Baixa & Alta & Média & Média & Não-Apto & Não-Apto & Apto & Conservação & $x$ & Conservação \\
\hline 3 & Muito Baixa & Muito Baixa & Muito Alta & Média & Baixa & Não-Apto & Não-Apto & Apto & Conservação & $x$ & Conservação \\
\hline 4 & Muito Baixa & Média & Alta & Alta & Alta & Não-Apto & Não-Apto & Apto & Conservação & $x$ & Conservação \\
\hline 5 & Muito Baixa & Baixa & Média & Alta & Média & Não-Apto & Não-Apto & Apto & Conservação & $\mathrm{x}$ & Conservação/Urbanização \\
\hline 6 & Muito Baixa & Baixa & Alta & Alta & Alta & Não-Apto & Apto & Apto & Urbanização & Conservação & Urbanização \\
\hline 7 & Muito Baixa & Muito Baixa & Alta & Muito Alta & Alta & Não-Apto & Apto & Apto & Conservação & Urbanização & Conservação \\
\hline 8 & Muito Baixa & Média & Alta & Alta & Alta & Apto & Não-Apto & Apto & Agricultura & Conservação & Conservação \\
\hline 9 & Baixa & Média & Alta & Média & Média & Apto & Não-Apto & Apto & Conservação & Agricultura & Conservação \\
\hline 10 & Baixa & Média & Alta & Baixa & Média & Apto & Não-Apto & Apto & Agricultura & Conservação & Agricultura \\
\hline 11 & Baixa & Média & Muito Alta & Média & Alta & Apto & Não-Apto & Apto & Agricultura & Conservação & Agricultura \\
\hline 12 & Baixa & Média & Alta & Média & Média & Apto & Não-Apto & Apto & Agricultura & Conservação & Agricultura \\
\hline 13 & Média & Muito Alta & Alta & Média & Alta & Não-Apto & Não-Apto & Apto & Conservação & $\mathrm{x}$ & Conservação \\
\hline 14 & Muito Alta & Muito Alta & Alta & Alta & Muito Alta & Apto & Não-Apto & Apto & Conservação & Agricultura & Conservação \\
\hline 15 & Muito Alta & Muito Alta & Alta & Alta & Muito Alta & Apto & Não-Apto & Apto & Conservação & Agricultura & Conservação \\
\hline 16 & Muito Alta & Muito Alta & Alta & Média & Muito Alta & Não-Apto & Não-Apto & Apto & Conservação & $\mathrm{x}$ & Conservação \\
\hline
\end{tabular}


A Figura 7a mostra o mapa de uso e cobertura da terra originado pela EMBRAPA (2004).

Pode-se observar que na região do Pantanal, a classe de maior ocorrência é a Savana com $81.773 \mathrm{~km}^{2}$, seguida da classe Ecótono, com $26.000 \mathrm{~km}^{2}$. Na terceira posição encontra-se a classe Pecuária que corresponde a $16.922 \mathrm{~km}^{2}$, seguida pela Savana Estépica com 12.762 km². As classes de menor ocorrência na região são compostas por Floresta Estacional Semi-Decidual $\left(6.453 \mathrm{~km}^{2}\right)$, Formações Pioneiras $\left(6.230 \mathrm{~km}^{2}\right)$, Hidrografia $\left(2.620 \mathrm{~km}^{2}\right)$, Floresta Estacional Decidual $\left(1.518 \mathrm{~km}^{2}\right)$ e Encrave $\left(1.310 \mathrm{~km}^{2}\right)$. As classes restantes foram pouco representativas na área de estudo, possuindo menos de $1000 \mathrm{~km}^{2}$ de extensão.

A Figura 7b mostra o modelo de ocupação e uso sugerido para o Bioma Pantanal. A área de estudo, localizada na porção centro-oeste do Brasil, apresenta quatro patamares bem definidos para o uso e cobertura da terra. O Bioma pantanal possui uma grande área de vegetação nativa, encontrando-se pequenos núcleos habitacionais pela região. Desta forma, com base nas políticas sustentáveis, optou-se por um modelo de desenvolvimento econômico que se baseia nas potencialidades naturais da região, como o ecoturismo e $o$ turismo de aventura. Consequentemente foram deliberadas, com base nas informações descritas e nas aptidões de cada domínio paisagístico, as áreas potenciais para os seguintes usos: a) as áreas correspondentes à planície aluvial inundável devem ser alvo de uma política ambiental voltada ao turismo ecológico e promovendo a conservação da área em questão; b) as áreas da planície aluvial sem a presença de inundações periódicas e com baixa declividade devem ser voltadas principalmente à conservação, porém, uma política de uso agrícola/pecuária em pequenas unidades pode ser admitida desde que haja uma compensação ambiental; c) as áreas correspondentes à planície aluvial não inundável $(50-150 \mathrm{~m})$ com predominância de declividade plana a baixa $(0-2,5 \%)$ com sedimentos arenosos do Pleistoceno, com solo predominantemente do tipo Plintossolo Háplico devem ser alvo de uma política de planejamento urbano; d) as demais regiões que correspondem a áreas de planalto com solos férteis devem proporcionar a agricultura e pecuária para suprir a demanda regional.

(a)

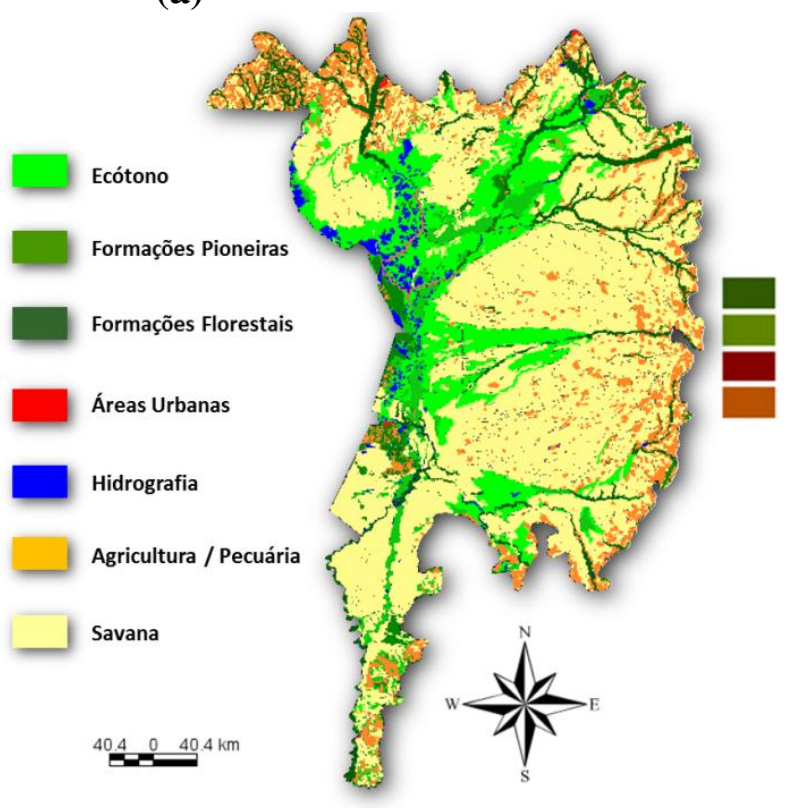

(b)

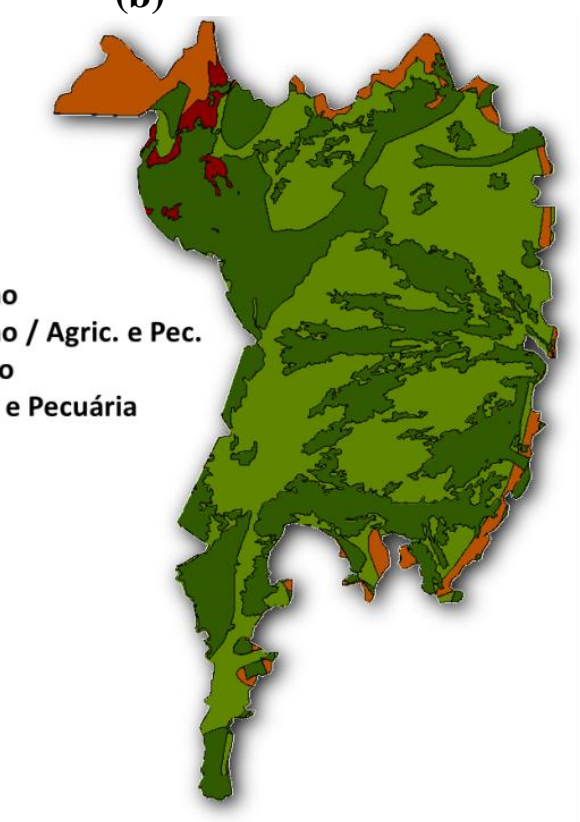

Figura 7. (a) Mapa de uso e cobertura da terra para o Bioma Pantanal (EMBRAPA, 2004); (b) Modelo de ocupação e uso para o Bioma Pantanal estimado a partir das unidades morfométricas, geologia e solos. 
Comparando o mapa de uso e cobertura da terra representado na Figura 7a com o modelo de ocupação e uso para o Bioma Pantanal (Figura 7b) percebe-se uma boa coerência entre o atual e o sugerido uso e cobertura da terra. Aproximadamente $45 \%$ da área total do bioma pantanal foram destinadas à conservação ambiental e para o desenvolvimento de um turismo sustentável. Estas áreas correspondem a áreas de Ecótono, savanas inundáveis e áreas de savana florestada, savana arborizada, savana estépica, entre outras. Aproximadamente $8 \%$ da área total foram destinadas unicamente à agricultura/pecuária, localizadas principalmente na região norte do bioma e em suas extremidades. Para este uso, percebe-se uma grande coerência com o modelo de ocupação e uso proposto, principalmente nas extremidades do bioma e na região norte. Porém, percebe-se uma tendência de crescimento de áreas agrícolas na planície aluvial com e sem inundações periódicas. Consequentemente, o avanço da agricultura requer medidas mitigadoras para prevenir o impacto deste uso na conservação e na biodiversidade.

De acordo com o mapa da EMBRAPA (2004), as áreas urbanas correspondem a $115 \mathrm{~km}^{2}$, ou seja, aproximadamente $0,07 \%$ da área total do bioma. No modelo proposto, destinaram-se aproximadamente $1 \%$ para a ocupação urbana, estas estão localizadas principalmente em áreas próximas ao núcleo agrícola na região norte. A área restante, $44 \%$, foi destinada à conservação e a agricultura/pecuária e correspondem praticamente a regiões de planície aluvial não inundável (50-150 m) com predominância de baixa declividade (0-2,5\%) com sedimentos arenosos e argilosos, podendo incluir sedimentos argilo-carbonáticos e cascalhos, com solo predominantemente do tipo Espodossolo Ferrocárbico. Para o uso agrícola, medidas de correção de solo e rotatividade de culturas devem ser adotadas. Ainda, a pecuária bovina, principalmente, é responsável pela maior incidência de desmatamentos na área de estudo, uma vez que acabam suprimindo áreas de Savana Estépica Florestada, Savana Estépica Arborizada, áreas de Ecótono entre Savana/Floresta Estacional Decidual, entre outras.

\section{CONCLUSÃO}

O estudo geoecológico da paisagem permite o diagnóstico da fragmentação dos geossistemas de um determinado ambiente ou bioma. Esta abordagem permite a integração dos elementos que compõe o meio, compreendendo a análise da interação e interdependência dos elementos ambientais e sociais. Desta forma, os dados de sensoriamento remoto provenientes de plataformas orbitais possibilitam a obtenção de informações multiespectrais com variadas resoluções espaciais e temporais. Estas informações podem ser empregadas para o estudo da variabilidade intra e interanual das áreas alagadas, propiciando a inclusão desta variável no estudo das unidades de paisagem do Bioma Pantanal.

A análise multitemporal dos dados de NDVI e reflectância da superfície, proporcionaram a integração de mapas altimétricos com informações da variabilidade do uso e cobertura da terra para o Bioma Pantanal, originando fragmentações para a área de estudo a partir da separação das planícies aluviais não inundáveis e inundáveis. Consequentemente, a partir do cruzamento de produtos orbitais e cartográficos foram identificadas 16 unidades de paisagem. Destas, as mais importantes destacam-se áreas de planície aluvial sujeita a inundações periódicas com predominância de declividade plana a baixa, compostas por sedimentos arenosos e argilosos e por planícies aluviais não inundáveis com sedimentos arenosos e argilosos, podendo incluir sedimentos argilo-carbonáticos e cascalhos.

Ainda, pode-se concluir que o desenvolvimento socioeconômico da região do Pantanal e em áreas adjacentes permitiu a expansão da fronteira agrícola, introduzindo ao bioma extensas áreas de pecuária e agricultura. Desta forma, o modelo de ocupação e uso pode inferir políticas públicas voltadas à otimização dos recursos naturais e ao desenvolvimento sustentável da região. 


\section{AGRADECIMENTOS}

À Fundação de Amparo à Pesquisa do Estado de São Paulo (FAPESP) pelo apoio (2010/07083-0).

\section{REFERÊNCIAS}

ADAMOLI, J. Zoneamento ecológico do Pantanal baseado no regime de inundações. In: ENCONTRO SOBRE SENSORIAMENTO REMOTO APLICADO A ESTUDOS NO PANTANAL, 1., 1995, Corumbá. Resumos... 1995. p.15-17. Disponível em: <http://mtcm12.sid.inpe.br/col/sid.inpe.br/mtc-m12@80/2006/08.17.11.54/doc/ @ sumario.htm>. Acesso em: 18 abr. 2012.

ASSINE, M. River avulsions on the Taquari megafan, Pantanal wetland, Brazil. Geomorphology, v. 70, n. 3/4, p. 357-371, 2005. doi: 10.1016/j.geomorph.2005.02.013. http://dx.doi.org/10.1016/j.geomorph.2005.02.013

ASSINE, M. L.; SOARES, P. C. Quaternary of the Pantanal, westcentral Brazil. Quaternary International, v. 114, p. 23-34, 2004. http://dx.doi.org/10.1016/S1040-6182(03)00039-9

BRASIL. Ministério do Meio Ambiente. Projeto de monitoramento do desmatamento dos biomas brasileiros por satélite. Monitoramento do bioma Pantanal. Brasília, DF, 30 p. 2010. Disponível em: <http://siscom.ibama.gov.br/monitorabiomas/pantanal/ RELATORIO_PANTANAL_2008_PMDBBS.pdf>. Acesso em: 18 abr. 2012.

CARDOZO, F. S.; PEREIRA, L. O.; MOURA, Y. M.; PEREIRA, G.; KAMPEL, M.; SHIMABUKURO, Y. E. et al. Utilização de parâmetros biofísicos para a estimativa de áreas alagadas no bioma Pantanal. In: SIMPÓSIO DE GEOTECNOLOGIAS NO PANTANAL, 3., 2010, Cáceres. Anais eletrônicos... 2010. p. 809-817. Disponível em: <http://www.geopantanal2009.cnptia.embrapa.br/2010/cd/geopantanal.pdf>. Acesso em: 18 abr. 2012.

EMPRESA BRASILEIRA DE PESQUISA AGROPECUÁRIA - EMBRAPA. Levantamento e mapeamento dos remanescentes da cobertura vegetal do bioma Pantanal, período de 2002 na escala de 1:250.000. Campinas: Embrapa Informática Agropecuária, 2004. p. 43.

INSTITUTO BRASILEIRO DE GEOGRAFIA E ESTATÍSTICA - IBGE. Mapas interativos. 2011. Disponível em: <http://www.ibge.gov.br>. Acesso em: 10 out. 2011.

JUSTICE, C. O.; GIGLIO, L.; KORONTZI, S.; OWENS, J.; MRISETTE, J.; ROY, D. et al. The MODIS fire product. Remote Sensing of Environment, v. 83, p. 244-262, 2002.

http://dx.doi.org/10.1016/S0034-4257(02)00076-7

PEREIRA, L. O.; CARDOZO, F. S.; MOURA, Y. M.; FONSECA, L. M. G.; PEREIRA, G.; MORAES, E. C. Delimitação das áreas alagadas do Pantanal a partir da análise por Componentes Principais e Transformada Wavelet. In: SIMPÓSIO DE GEOTECNOLOGIAS NO PANTANAL, 3., 2010, Cáceres. Anais eletrônicos... 2010a. p. 200-209. . Disponível em: <http://www.geopantanal2009.cnptia.embrapa.br/2010/ cd/geopantanal.pdf $>$. Acesso em: 18 abr. 2012. 
PEREIRA, G. ; SILVA, M. E. S.; MORAES, E. C.; SHIMABUKURO, Y. E.; CARDOZO, F. S.; SILVA, F. B. et al. Impactos climáticos das áreas alagadas no Bioma Pantanal. In: SIMPÓSIO DE GEOTECNOLOGIAS NO PANTANAL, 3., 2010, Cáceres. Anais eletrônicos... 2010b. Disponível em: <http://www.geopantanal2009.cnptia.embrapa.br /2010/cd/geopantanal.pdf>. Acesso em: 18 abr. 2012.

PRIEGO, A.; BOCCO, G.; MENDONZA, M.; GARRIDO, A. Propuesta para la generación semiautomatizada de unidades de paisajes: fundamentos y métodos. 2008. Disponível em: <http://www2.ine.gob.mx/emapas/download/paisaje_unidades_ paisaje.pdf>. Acesso em: 18 abr. 2012.

RABUS, B.; EINEDER, M.; ROTH, A.; BAMLER, R. The shuttle radar topography mission- a new class of digital elevation models acquired by spaceborne radar. ISPRS Journal of Photogrammetry and Remote Sensing, v. 57, n. 4, p. 241-262, 2003. http://dx.doi.org/10.1016/S0924-2716(02)00124-7

RAMON, A. M.; SALINAS, E.; REMOND, R. Diseño metodológico para la elaboración de mapas de paisajes con el uso de los SIG: aplicación a la cuenca alta del río Cauto, Cuba. Geografía y Sistemas de Información Geográfica, ano 1, n. 1, p. 95-108, 2009.

ROSS, J. L. S. Análise empírica da fragilidade dos ambientes naturais e antropizados. RDG Revista do Departamento de Geografia, São Paulo, n. 8, p. 63-74, 1994.

SALINAS CHÁVEZ, E.; MIDDLETON, J. La ecología del paisaje como base para el desarrollo sustentable en América Latina. 1998. Disponível em: <http://www.brocku.ca/tren/EPI/lebk/lopez1.html>. Acesso em: 18 abr. 2012.

SALINAS, E.; QUINTELA, J. Paisajes y ordenamiento territorial: obtención del mapa de paisajes del Estado de Hidalgo en México a escala media con el apoyo de los SIG, Alquibla. Revista de Investigaciones del Bajo Segura, Alicante, n. 7, p.517-527, 2000.

SALINAS ESCOBAR, M. E. (Org.). El ordenamiento territorial: experiencias internacionales. Secretaría del Medio Ambiente y Recursos Naturales. 2008. Disponível em: <http://www2.ine.gob.mx/publicaciones/download/596.pdf>. Acesso em: 18 abr. 2012.

SISTEMA de processamento de informações georreferenciadas - SPRING. Versão 4.3. São José dos Campos: INPE, 2005. 